\title{
Kreasi Bros Dan Pincushion Dari Kain Perca Hasil Karya Penerima Manfaat Jurusan Menjahit Di Balai Rehabilitasi Sosial "Taruna Yodha" Sukoharjo
}

\author{
Rachmi Kurnia Mulyana ${ }^{1}$, Slamet Supriyadi², Zaini Rohmad ${ }^{3}$ \\ 1,2Prodi Pendidikan Seni UNS \\ ${ }^{3}$ Prodi Pendidikan Sosiologi Antropologi UNS \\ ${ }^{1}$ rchmia77@gmail.com
}

Pada Balai Rehabilitasi Sosial Taruna Yodha Sukoharjo, kain perca yang merupakan sisa dari jurusan menjahit di sana masih terabaikan dan belum dimanfaatkan secara maksimal oleh pihak balai. Kain perca yang terabaikan dapat diolah lebih lanjut menjadi kerajinan yang memiliki nilai ekonomi yang disesuaikan dengan tren masyarakat masa kini. Bros dan pincushion merupakan produk olahan kain perca yang berkaitan dengan hijab, yang diminati oleh masyarakat. Pembuatan bros dan pincushion bersama penerima manfaat di balai dilakukan dengan metode demonstrasi, dan data yang diperoleh diolah secara kualitatif. Hasil yang diperoleh adalah karya berupa bros dan pincushion, kemudian hasil karya tersebut dikemas secara menarik untuk selanjutnya dapat dipamerkan dan dijual oleh pihak balai pada showroom yang menyajikan karya penerima manfaat pada balai tersebut.

Kata kunci: kain perca, pemberdayaan, bros, pincushion

\section{Broaches and Pincushion Creations from Patchwork: Attainment of the Sewing Major Beneficiaries at the Social Rehabilitation Center}

At Sukoharjo Tarun Yodha Social Rehabilitation Center, patchworks which are left over from the sewing department were still neglected and have not been fully utilized by the hall. Neglected patchworks can be processed further into crafts and afterwards could have economic values that are adjusted to the trends of today's society. Broaches and pincushion are patchwork processed products related to hijab, which are in demand by the public. Broaches and pincushion making with the beneficiaries at the social rehabilitation center were carried out by demonstration methods, and the data obtained was processed qualitatively. The results obtained are works in the form of broaches and pincushion, then the works are packaged in an interesting manner and can then be exhibited and sold by the Center in the showroom which presents the work of the beneficiaries at the Center.

Keywords: patchwork, empowerment, brooch, pincushion.

Proses Review : 1 - 20 Agustus 2019, Dinyatakan Lolos: 22 Agustus 2019 


\section{PENDAHULUAN}

Balai Rehabilitasi Sosial "Taruna Yodha" Sukoharjo yang beralamatkan di Kecamatan Sukoharjo, Kabupaten Sukoharjo, Jawa Tengah, kodepos 57512. Balai ini merupakan balai milik dinas sosial provinsi Jawa Tengah yang membina puluhan remaja putri dan putra yang berusia 13-25 tahun yang menganggur akibat putus sekolah maupun alasan lainnya. Anak-anak binaan akan disebut sebagai penerima manfaat oleh pihak balai. Mereka diberi beraneka ragam ketrampilan selama kurang lebih 4-6 bulan dan diasramakan. Penerima manfaat akan diberi bekal ilmu sesuai dengan minat mereka dimana terdapat beberapa kursus di Balai Rehabilitasi Sosial "Taruna Yodha" Sukoharjo seperti menjahit, salon, bengkel, las dan tata boga.

Pembelajaran yang terdapat pada Balai Rehabilitasi Sosial "Taruna Yodha" Sukoharjo termasuk dalam pendidikan nonformal. Pendidikan nonformal merupakan salah adalah setiap kegiatan pendidikan yang terorganisir yang diselenggarakan diluar sistem formal, baik tersendiri maupun merupakan bagian dari suatu kegiatan yang luas, yang dimaksudkan untuk memberikan layanan kepada sasaran didik tertentu dalam mencapai tujuan-tujuan belajar (Soelaman Joesoef, 1999:50).

Salah satu jurusan yang sering dipilih oleh penerima manfaat di balai tersebut adalah jurusan menjahit. Pada jurusan ini terdapat ketrampilan menjahit pakaian mulai dari pakaian wanita, pria dan anak. Ketrampilan yang diberikan oleh pihak balai pada jurusan ini hanya sebatas pada ketrampilan menjahit pakaian saja, sehingga apabila terdapat bahan sisa dari kain-kain yang mereka pakai, yakni kain perca, belum mereka olah secara maksimal.

Menurut Kurrien Zakiya (2005:19) kain perca merupakan, "Potongan bahan/kain perca, baju yang telah sobek, sisa-sisa kain jahitan yang terbuang, biasanya mudah ditemukan di tempat tukang jahit, yang mempunyai corak dan warna serta tekstur yang berbeda, misalnya polos, bergambar, ataupun bergaris, yang dapat dimanfaatkan untuk berbagai macam karya.“

Kain perca dapat diolah kembali menjadi produk kerajinan yang memiliki nilai jual. Penerima manfaat diajak untuk memanfaat kain perca yang terbuang menjadi aksesoris perempuan. Aksesoris yang sering digunakan oleh banyak perempuan, terutama yang berhijab adalah bros, selain bros dibuat pula pincushion. Pincushion merupakan tempat untuk meletakkan jarum pentul yang merupakan barang keseharian perempuan berhijab. Ketika lulus nanti selain keahlian utama yakni menjahit pakaian, penerima manfaat diharapkan dapat membuat dan menjual bros dan pincushion yang dibuat dari kain sisa jahitan.

Bros adalah benda perhiasan dekoratif yang dirancang agar dapat terpasang disematkan ke pakaian atau media lain. Pada bagian belakang bros terdapat jarum dan kait seperti peniti untuk menyematkan perhiasan ini pada kain. (https://id.wikipedia.org/wiki/Bros)

Bros merupakan aksesoris jilbab yang populer, dan hampir setiap wanita berjilbab memilikinya. Aksesoris bros dari kain perca juga cukup diminati oleh konsumen, hal inidikarenakan wujudnya yang unik dan harganya yang terjangkau. Bros dari kain perca juga cukup mudah dan cepat dibuat.

Pincushion adalah aksesoris berupa bantalan yang digunakan untuk menyematkan jarum, yang dapat beraneka ragam wujudnya. Bros dan pincushion tersebut dibuat oleh penerima manfaat dengan cara berkelompok selama satu hari pertemuan.

Berdasarkan latar belakang yang dikemukakan sebelumnya maka dapat dirumuskan masalah sebagai berikut:

1. Bagaimana pemanfaatan limbah kain perca di Balai Rehabilitasi Sosial "Taruna Yodha" Sukoharjo yang diolah menjadi bros dan pincushion?

2. Bagaimana wujud karya bros dan pincushion yang dihasilkan oleh penerima manfaat di Balai Rehabilitasi Sosial "Taruna Yodha" Sukoharjo?

\section{METODE}

Metode penulisan yang digunakan untuk penelitian ini yakni kualitatif, dikarenakan data yang diperoleh jauh dari kesan statistik. Pada pelaksanaan penelitian, pembelajaran akan disampaikan dengan metode demonstrasi. Syaiful Sagala (2011:210) mengemukakan bahwa metode demonstrasi adalah pertunjukan tentang terjadinya sesuatu atau peristiwa sampai pada tingkah laku yang dapat dicontohkan agar dapat diketahui dan dipahami siswa secara nyata. Peneliti akan mendemonstrasikan cara membuat bros dan pincushion untuk kemudian ditirukan oleh penerima manfaat disana.

\section{HASIL DAN PEMBAHASAN}

Pelaksanaan pembuatan bros dan pincushion bersama penerima manfaat terdiri dari dua tahapan dimana tahapan pertama adalah tahapan persiapan dan tahapan kedua adalah pelaksanaan. Pada tahap pelaksanaan dilakukan selama satu hari, karena untuk membuat aksesoris tersebut tidak membutuhkan waktu yang lama. Pelaksanaan diadakan pada hari Sabtu, 24 Desember 2016 pagi pukul 09.00 hingga selsesai.

\section{Tahap Perencanaan dan Persiapan}

a. Peneliti mensurvei lokasi, dan menemukan banyak terdapat limbah kain sisa pelajaran menjahit yang tidak digunakan.

b. Peneliti mencari materi mengenai cara membuat bros dan pincushion dari kain perca dan kemudian dimod- 
ifikasi agar dapat diterima penerima manfaat. Peneliti memutuskan untuk mengajarkan membuat bros berbentuk bunga, yang popular di kalangan perempuan berhijab. Pincushion yang dibuat berbentuk cupcake, dikarenakan cara membuatnya mudah dan berwujud unik.

c. Peneliti membuat bros dan pincushion yang dijadikan sebagai contoh karya.

d. Peneliti mempersiapkan alat dan bahan untuk membuat bros dan bando dari kain perca, yakni:

Alat:

1. Tembakan dan lem tembak

2. Gunting

3. Jarum jahit

4. Benang

Bahan:

1. Kain perca (sisa pelajaran menjahit)

2. Peniti bros

3. Cup kertas es krim

4. Kancing untuk hiasan

5. Manik-manik untuk hiasan

Tahap Pelaksanaan dan Analisis Data

Pada tahap pelaksanaan, disampaikan materi yang diberikan melalui metode demonstrasi, dimana peneliti mencontohkan cara membuat karya kepada penerima manfaat sebelum mereka membuat karya. Pelaksanaan pembuatan bros dan pincushion ini dilakukan di aula Balai Rehabilitasi Sosial "Taruna Yodha" Sukoharjo selama satu kali pertemuan yakni Sabtu tanggal 24 Desember 2016 pada pukul 09.00 hingga selesai, dan dilakukan analisis data mengenai proses pembelajaran yang berlangsung tersebut dengan pendeskripsian sebagai berikut.

Peneliti mula-mula memperkenalkan diri, kemudian menunjukan contoh karya bros dan pincushion dari kain perca dan penerima manfaat melihat-lihat karya tersebut.

Selanjutnya penerima manfaat dibentuk kelompok. Ketua kelompok dipilihkan oleh guru menjahit di balai tersebut. Ketua kelompok dipilih berdasarkan ketangkasan mereka dalam pelajaran menjahit. Anggota kelompok dipilih secara acak dengan cara diundi. Pada pertemuan ini terbentuk 5 kelompok yang masing- masingnya beranggotakan dua hingga tiga orang, yaitu:

1. Kelompok hitam: Istiqomah (ketua), Aprilia Dwi Lestari, Yuyun Susilowati, Siti Muawanah

2. Kelompok merah: Ela Safitri (ketua), Nurul Lathifatul Hidayah, Wahyu Mulyani

3. Kelompok kuning: Nurul Alfiaturrahmaniah (ketua), Meisyi Navira, Susan Ning Rahayu

4. Kelompok Biru: Bagus Setyawan (ketua), Ayu Setyaningsih, Yati Ayuningtyas

5. Kelompok hijau: Titik Rahayu (ketua), Nurinda Oktaviani, Nunik Murti Rahayu
Setelah terbentuk kelompok, peneliti mendemonstrasikan cara membuat bros dari kain perca dan penerima manfaat menyaksikan bersama. Hal pertama yang peneliti lakukan adalah membuat pola dari kain, kemudian pola tersebut dijahit dengan lipatan tertentu dan dirangkai menjadi bunga, kemudian bunga dihias dengan kancing dan manik-manik, serta direkatkan ke peniti bros. Peneliti kemudian menanyakan kepada penerima manfaat apabila ada yang kurang jelas, dan memperagakan kembali.

Seusai demonstrasi, peneliti mempersilahkan penerima manfaat untuk mengambil alat dan bahan yang telah disediakan. Penerima manfaat kemudian mulai membuat bros sesuai dengan instruksi peneliti, namun mereka dibebaskan untuk berkreasi sesuai dengan keinginan mereka sehingga bros berbentuk bunga ini beraneka ragam ukuran dan warnanya. Peneliti turut membantu penerima manfaat yang masih kesulitan dalam menjahit dan mengelem peniti bros.

Pembuatan bros ini berlangsung dengan cepat karena dilakukan secara kelompok. Ketika penerima manfaat telah menyelesaikan bros mereka, pembelajaran dilanjutkan dengan membuat pincushion.

Peneliti mendemontrasikan cara membuat pincushion berbentuk cupcake. Pertama, peneliti memperlihatkan pola kain berbentuk lingkaran dengan diameter $14 \mathrm{~cm}$, lalu kain berbentuk lingkaran tersebut dijahit jelujur pada tepiannya dan ditarik hingga berbentuk seperti mangkuk. Setelah berbentuk mangkuk, diisi dengan dakron hingga penuh dan dijahit Buntalan kain tersebut kemudian dijadikan satu dengan wadah es krim yang sebelumnya telah dilapisi kain. Wadah es krim tersebut di dalamnya dimasukkan pemberat berupa gumpalan koran agar wadah tampak kokoh. Setelah itu kemudian disatukan dengan menggunakan lem tembak, dan dihias menggunakan kancing

Seusai mendemontrasikan cara membuat pincushion, peneliti meminta penerima manfaat untuk berkreasi membuat pincushion sesuai dengan kelompoknya masing-masing. Penerima manfaat membuat karya pincushion sesuai dengan kelompoknya masing-masing. Waktu yang diperlukan juga tidak terlalu lama karena karya dikerjakan secara berkelompok.

Ketika sudah usai, seluruh karya peneima manfaat dikumpulkan. Hasil karya penerima manfaat jurusan menjahit Balai Rehabilitasi Sosial Taruna Yodha Sukoharjo adalah sebagai berikut.

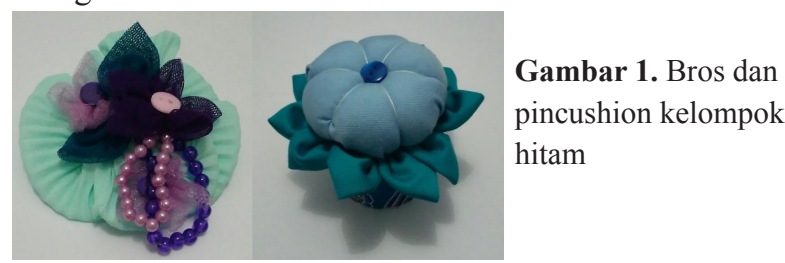




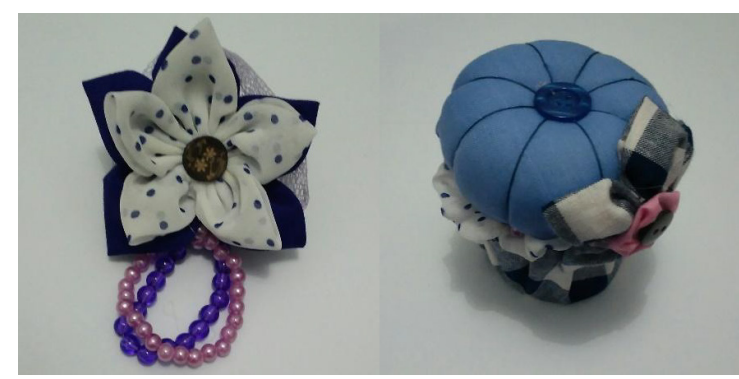

Gambar 2. Bros dan pincushion kelompok merah

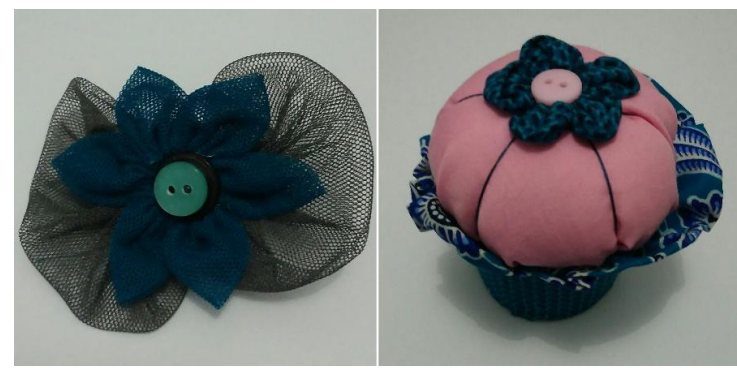

Gambar 3. Bros dan pincushion kelompok kuning

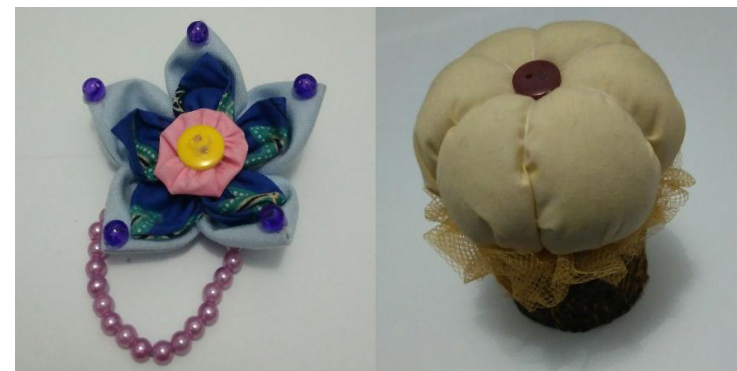

Gambar 4. Bros dan pincushion kelompok biru

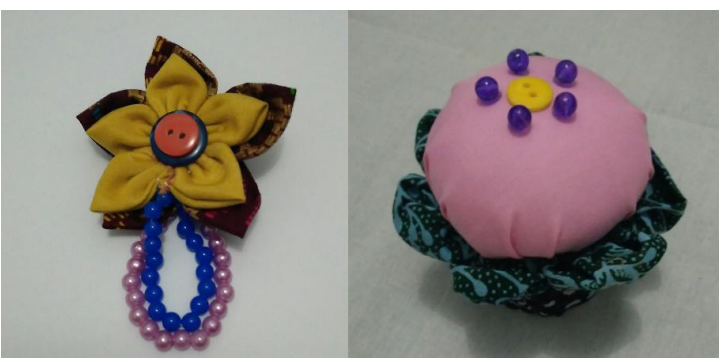

Gambar 5. Bros dan pincushion kelompok hijau

Karya penerima manfaat kemudian dikemas secara menarik, untuk kemudian dipajang di showroom menjahit yang terletak di bagian depan balai. Kemasan yang dipilih untuk produk adalah yang terbuat dari bahan mika, karena selain awet, kemasan mika membuat produk tetap terlihat wujud aslinya dan tampak lebih berkualitas daripada produk yang dibungkus dari plastik.

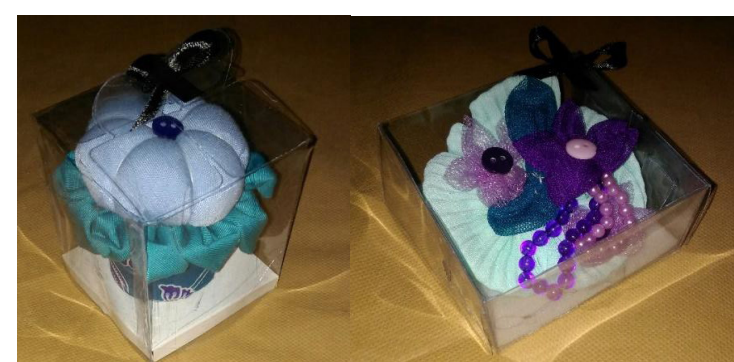

Gambar 6. Bros dan pincushion kelompok hitam yang telah dikemas

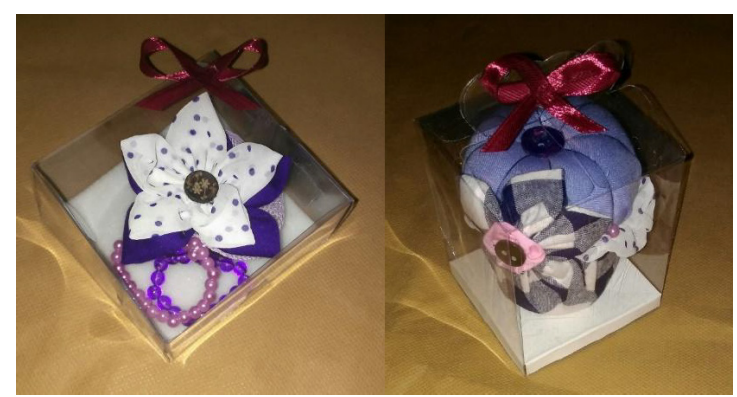

Gambar 7. Bros dan pincushion kelompok merah yang telah dikemas

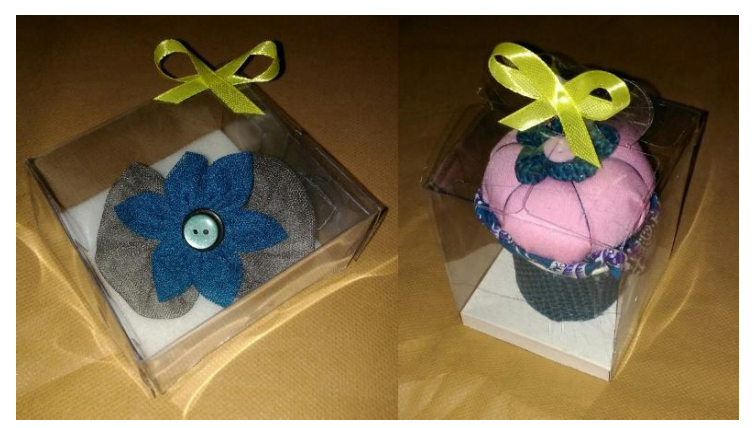

Gambar 8. Bros dan pincushion kelompok kuning yang telah dikemas

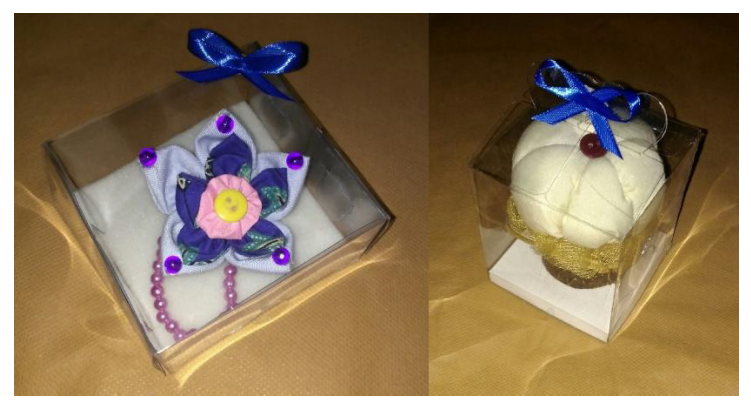

Gambar 9. Bros dan pincushion kelompok biru yang telah dikemas 


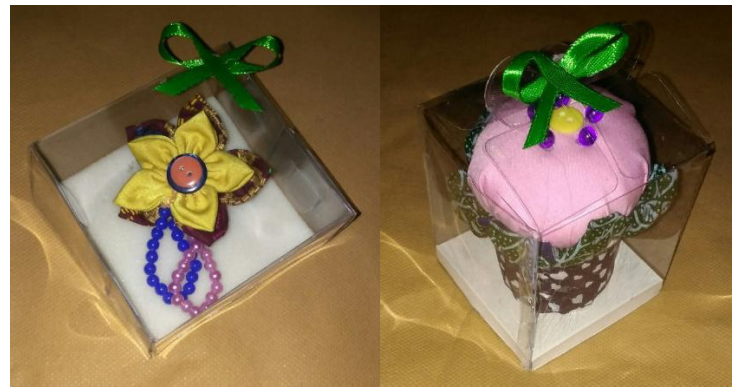

Gambar 9. Bros dan pincushion kelompok hijau yang telah dikemas

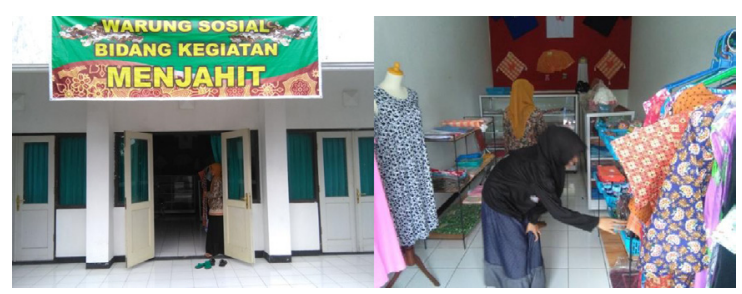

Gambar 10. Showroom menjahit dengan nama "Warung Sosial Bidang Kegiatan Menjahit”

\section{SIMPULAN}

Pembuatan bros dan pincushion dari kain perca oleh penerima manfaat Balai Rehabilitasi Sosial "Taruna Yodha" berlangsung lancar dengan hasil yang baik.

Potensi ekonomi yang baik terdapat pada karya bros dan pincushion dari kain perca, diharapkan kedepannya pihak balai dapat memasukan pembelajaran kain perca ke dalam kurikulum menjahit, agar penerima manfaat memperoleh ilmu selain menjahit pakaian.

\section{SARAN}

Berdasarkan simpulan yang diperoleh maka saran yang dapat diterapkan di Balai rehabilitasi Sosial Taruna Yodha adalah sebagai berikut:

1. Diharapkan pihak balai tidak lagi membuang kain perca yang dihasilkan dari pelajaran menjahit, namun mengolahnya kembali menjadi kreasi kerajinan yang layak jual.

2. Pembelajaran kreasi kain perca di Balai Rehabilitasi Sosial "Taruna Yodha" Sukoharjo menghasilkan karya ketrampilan yang memiliki potensi ekonomi, maka disarankan pihak balai untuk memasukkan pembelajaran kreasi kain perca ke dalam kegiatan inti yang dapat diikuti oleh seluruh penerima manfaat di balai tersebut, dan dibuatkan jam khusus untuk kreasi kain perca.

3. Pihak Balai Rehabilitasi Sosial "Taruna Yodha" Sukoharjo mencari pengajar professional yang mampu untuk mengajarkan kreasi kain perca disana, sehingga hasil yang didapatkan lebih berkualitas.

\section{DAFTAR RUJUKAN}

Joesoef, Soelaman. 1999.Konsep Dasar Pendidikan non formal.Jakarta: Bumi Aksara Sagala, Syaiful. 2011. Konsep dan Makna Pembelajaran. Bandung : Alfabeta Zakiya,

Kurrien. 2005. Memberdayakan Anak Belajar. Surabaya: Plan Indonesia https://id.wikipedia.org/wiki/Bros diunduh pada tanggal 28 Juli 2018 